\title{
Analysis of SEIMENS Class F Gas Turbine Protection System Lei Shi ${ }^{1, a}$,Dayu Chen ${ }^{1, b}$,Tongyue Qi ${ }^{1, c}$ \\ ${ }^{1}$ Beijing Jingneng GaoantunThermalPower Co.Ltd, Beijing City100024,China

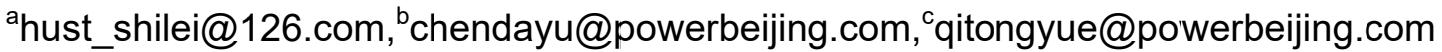

Keywords: Class F Gas Turbine, Protection System,SGT-4000F.

Abstract. Gas Turbine engine is the world's most advanced large equipment, at the same time maintain a very high price. It is the final front of the protection, thus it is very important. JingNenggaoan gas heating pant use Seimens SGT5-4000F gas turbine. As a typical model of Level F gas turbine, continued with many classical design. As a technical stuff in this industry, we have to know the contents and parts of the protection system, thus can avoid the damage and economic damage of equipment.

\section{Introduction}

The protection system of Seimens Gas Turbine is complicated, include two parts: the protection of hardware and software. For the part of the software protection, on the one hand by the method of logic prediction, on the other hand through safe automatic system. For the part of hardware protection, it was realized through the discontinued return circuit in the control cabinet. The following part will be the introduction of the process.

The composition and the realization of the protection system.Seimens SGT-4000F(4) composed by four parts: FM458 protection, T3000 protection, SCHLOSSER hardware protection and the protection of the order control of turbine[1].

Turbine has 103 thermoelectric instrument(not including the testing spot of generator winding). The unsafe condition detected by the instruments, get gas through ESV valve, pre-valve, on duty valve, make the gas stop[1]. Avoiding the further spread of the incident. Like showed in the Fig.1 of the valve and the system of the route of the gas (pre valve and on duty valve are just like this). ESV valve, pre valve and on duty valve are all control valve. These valves can be adjusted after latch on magnetic valve is on. Otherwise it will be closed under the pressure of the spring, as shown inFig. 1.
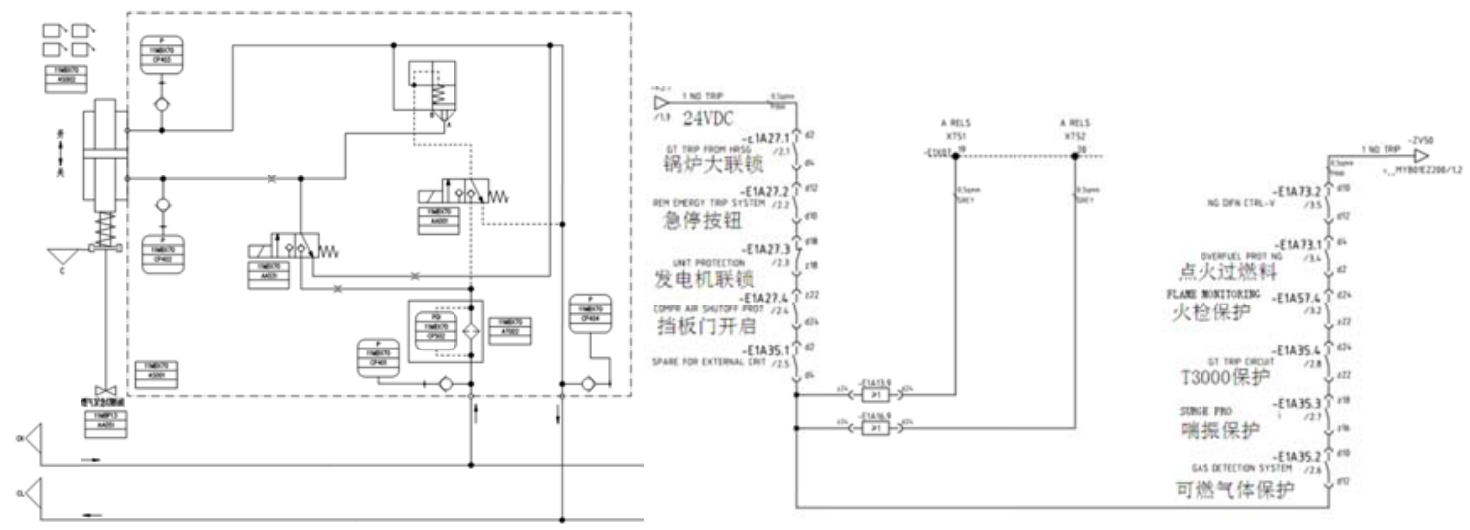

Fig. 1 ESV Control oil system diagram Fig. 2 Schloesser Hard wiring protection chain

Where ESV valve, pre valve, on duty valve's $24 \mathrm{~V}$ electric port all provided by SCHLOSSER hard wire serious connection circuit. Every discontinued spot can lead to the power shut down of latch-on magnetic valve. All of these spots are protected by one protection system,as showed in Fig. 2.

Including lock of the furnace, lock of the engine, hand emergency brake, the protection of the panel, the protection of the leak inflammable gas, ant surge system, protection of the fire detecting 
system, ignition protection system, over speed protection system, all connect to the protection chain by hard wire. Bearing bush vibration, bearing bush heat, all valve connect to the spot by ESV valve, pre valve, just as T3000 protection linking spot). When operating on any spot, closing valve discontinue, no electricity going through, operation system has no liquid pressure. Valve under the pressure close fast, protecting the clutch through discontinues fuel.

There are two routes, and other two protection routes (operation ESV), under normal conditions, these four routes are have electricity goes through. Any route disconnect to electricity will lead to the close of valve.

Other than this, still other 6 ways to protect, including through disconnecting ESV valve lubricating oil and pressure of the protecting shell. When all these protections are in order, the order control of TCS can be triggered, all of the engine will stop in order.

\section{Burning engine protection system analyses}

Seimens have many protection programs, there are a dozen. Except programs have strong vibration, high temperature, high speed, still have many long lasting and classic protection systems. For example heat acceleration protection, I will introduce to you some classis program.

Engine shut down protection. Outside the engine room there are two fire detecting equipents. Fuel is not allowed to go into the engine for a long time if the engine is not burning or shut down, that can prevent major blast from happening[3]. The fire detect equipment can achieve this by monitoring the conditions of the flame. It needs to be installed on every spot. Like in Fig. 4 showed. It is not monitoring every single spot but the formation of the valves, about 2-4 valves.

Fire protection has three mian lines, like showed in the following grahic:

1) After the order of the ESV valve, if not detect the two fire in 12 seconds, then consider the fire is fail, disconnect the engine.

2) During operation two detector all perform the no flame discontinued engine policy

3) After the engine shut down, 10 seconds later ESV valve detect no flame, rebounded and discontinue the engine.

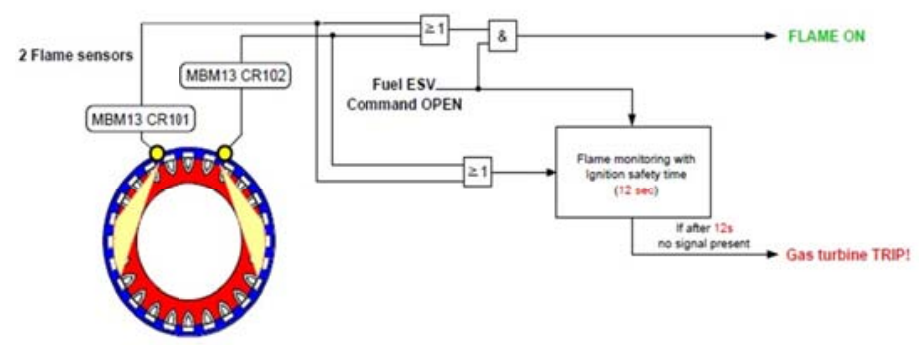

Fig. 3 Flame protection

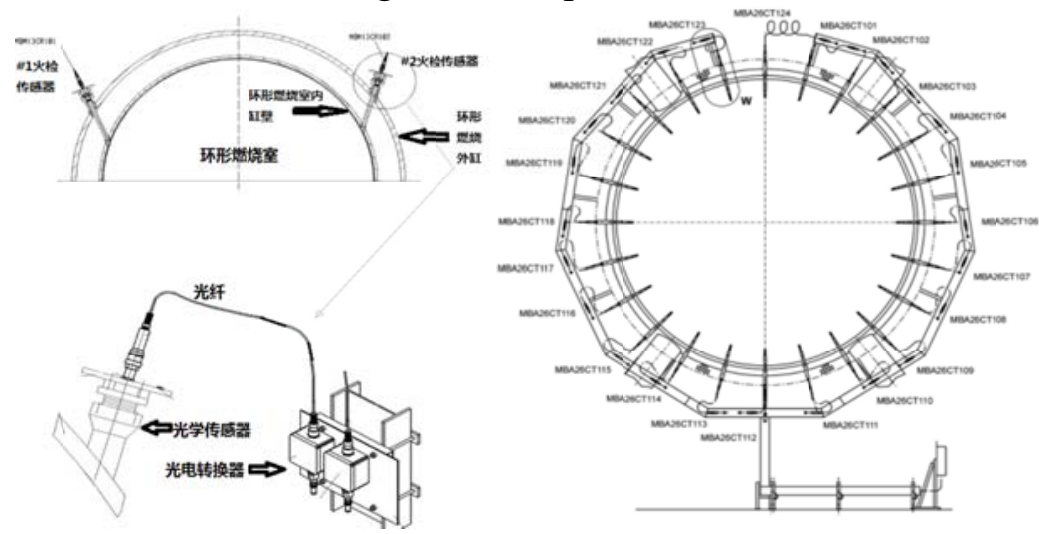

Fig. 4 Fire detector installation

Fig. 5 Air pipes-heating electric dual-arrange around the clock

Engine air temperature protection system. When the engine is operating normally, burning room's temperature must be control under certain level, otherwise it can damage the strength and the gravity of the opponents[3]. 
The air temperature protection has three aspect: burning area (protection systems), engine parts 'temperature rise (burning engine parts has rapid temperature rise, monitor can put out the fire) and uneven over heated (some spots).

Air temperature is installed in the end of the pipes which consisted of three branches of 24 pieces of heat electricity dual (MBA26CT101-124). All the 24 electric pipes dual installed behind turbine. If cumulated as $\mathrm{B}$ and $\mathrm{C}$ heat temperature, set pillar $\mathrm{A}$ as spare, the follow photo showed:

Air temperature is set by the following three:

1) The over-heated protection of the engine:

(1) Air temperature choose 6 out of 24 as signal testing points $(1 \mathrm{~B}, 5 \mathrm{~B}, 9 \mathrm{~B}, 13 \mathrm{~B}, 17 \mathrm{~B}, 21 \mathrm{~B})$. The protection and alarm set by the principle of 3 out of 6 . The temperature all above 658 degrees. The correct number of the temperature (air goes into the pressure popes, open air temperature and auto correction), the valve shall stop.

(2) If 6 signals $(1 、 5 、 9 、 13 、 17,21), 3$ out of 6 has broken, engine shut down, its logic framework as shown in Fig. 6.
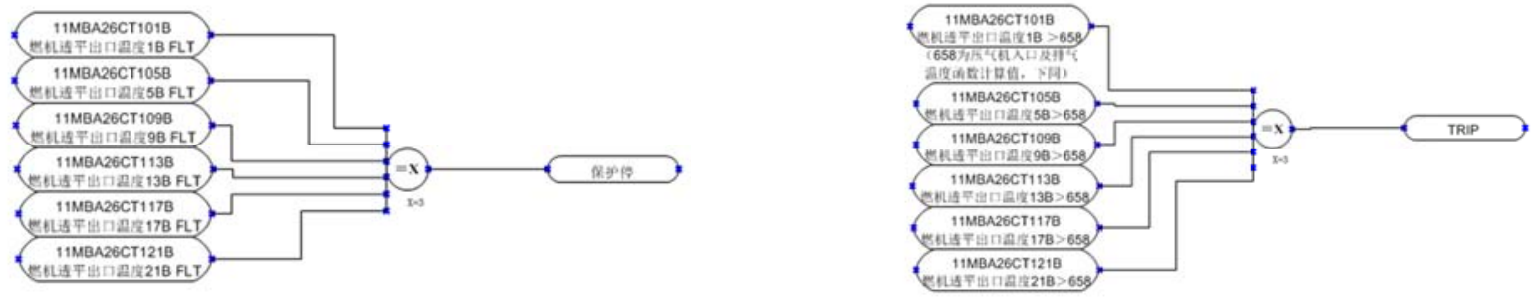

Fig. 6 Logic framework of the air temperature protection I

2) Supervision on engine shut down (cold spot protection):

(1) If the neighboring 2 heat dual $\mathrm{B}$ and $\mathrm{C}$ signal all below the average 50 degree, should sent alarm:

(2) If the neighboring 3 heat dual $\mathrm{B}$ and $\mathrm{C}$ all below the average 50 degree, the engine stops:

(3) If the neighboring 4 heat dual $\mathrm{B}$ and $\mathrm{C}$ all below the testing average 50 degree, or any two sets in three consecutive manner below average 50 degree, engine shut down.

3) Part supervision on high temperature

(1) 24 Branch electricity signal, if any of the branch's temperature is high (both for $\mathrm{B} / \mathrm{C}$ ), average is above 50 degree, the valve shall break

(2) If situation happens when B or C break at the same time, engine go into the paluse status, like logic Fig. 7 showed.
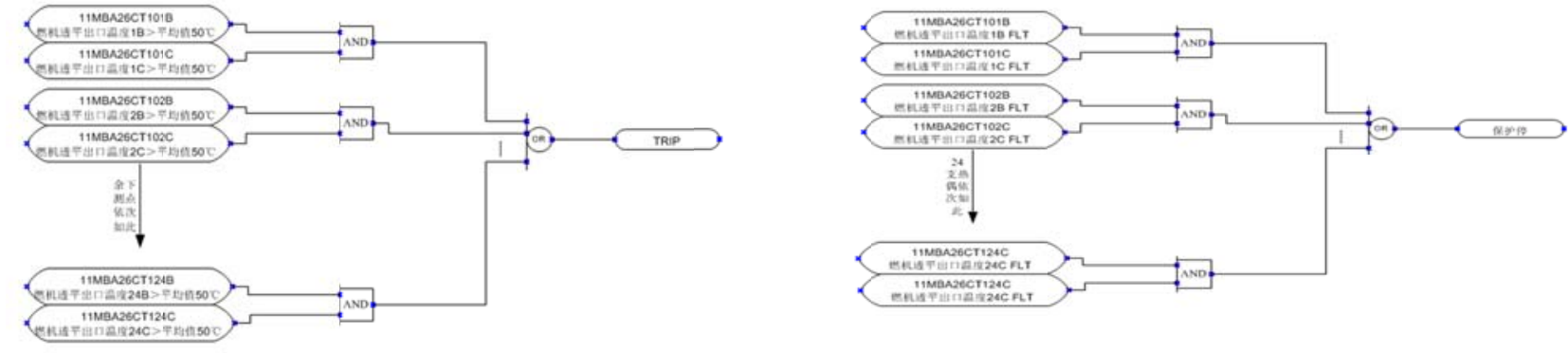

Fig. 7 Air temperature protection logic II

Engine burning room ACC protection. When engine is not stable, pressure and the vibration of the engine all increase. These conditions can be reflected by humming sensor and the number of the vibration of the burning tank. The vibration tank of the burning engine can cause damage, thus need to test and stop the damage in time. Vibration higher than $2.5 \mathrm{~g}$, if the accumulation time is longer than $30 \mathrm{~s}$, need to stop the engine and examine. Large scale of damage can occur when surpass the ultimate GW3[2]. When situation like this occur, the engine will stop working to prevent further damage. Every engine has three Swiss Vibro-Mete CA901 speed up detector, and installed on the outside of the burning tank. Through $3.5 \mathrm{~m}$ wire lead to the outside of the burning tank and connect with IPC704. Connect with VM600 and detect, ultimately transfer all the data to 
T3000 protection control system[2].ACC signal is calculated from the average number of the three (get the larger number when there is faulty occur. There are four levels:

The first level, showed in the Fig. 8, when burning engine speed up GWI $>2.5 \mathrm{~g}$, the faulty is not eliminated, engine lag $19 \mathrm{~s}$.

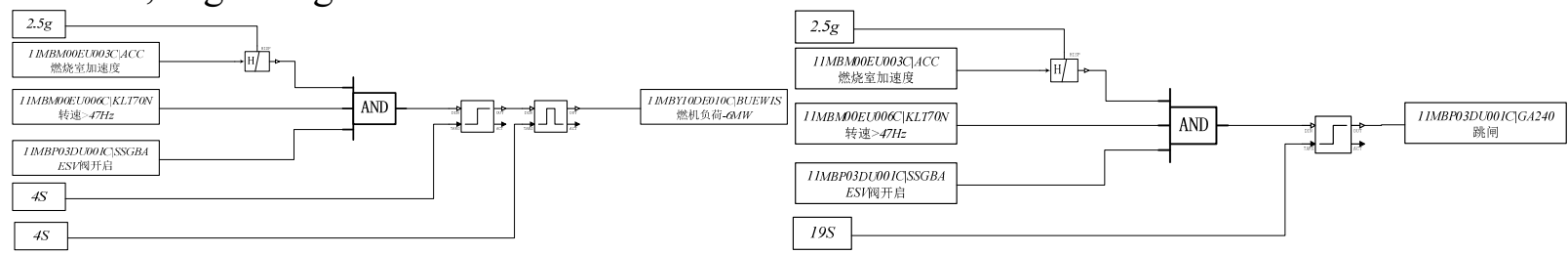

Fig. 8 Burning room protection logic framework I

The second level, showed in the Fig. 9, when burning engine speed up GWI $>3 \mathrm{~g}$, the faulty is not eliminated, engine lag $13 \mathrm{~s}$.

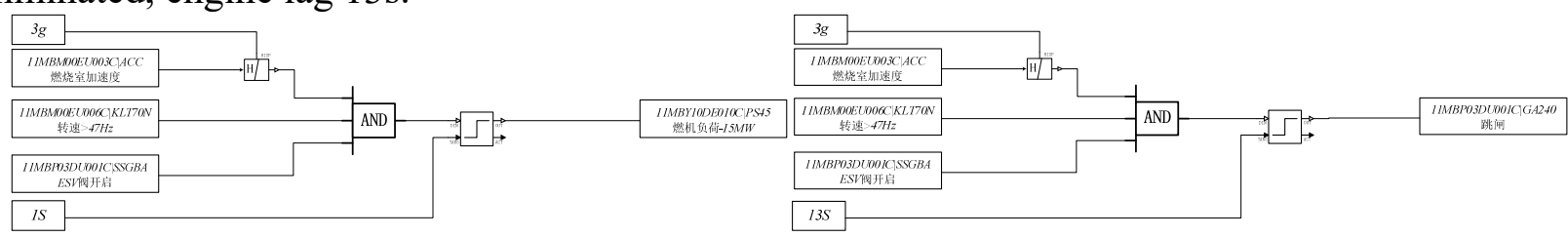

Fig. 9 Burning room speed up protection logic framework II

Just as showed in the Fig. 10, when burning room speed up GW>8g, the valve stops, need to examine the room

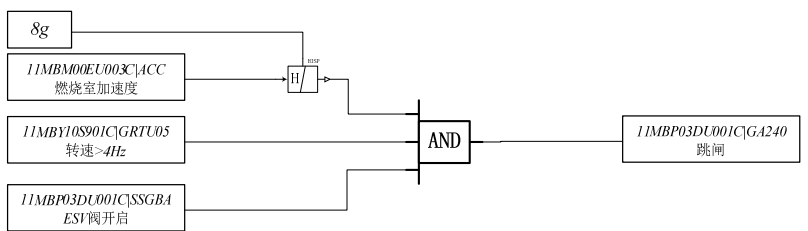

Fig. 10 Burning room speed up protection logic framework III

Level 4, when burning room is speed up GW4 $>2 \mathrm{~g}$ at the same time IGV $>95 \%$, drop $6 \mathrm{MW}$ weight in every $4 \mathrm{~s}$, if the fault is still there, then lag 19s (as Level 2)

Aside from that, in order to maintain smooth work of the sensor, have protection at the same time, vibration and speed up as faulty signal. When the engine is working above $47 \mathrm{~Hz}$ and the burning room is less than $0.1 \mathrm{~g}$, the there is fault. If three sensor all have faults, valve stops in 2 seconds. As showed in Fig. 11.

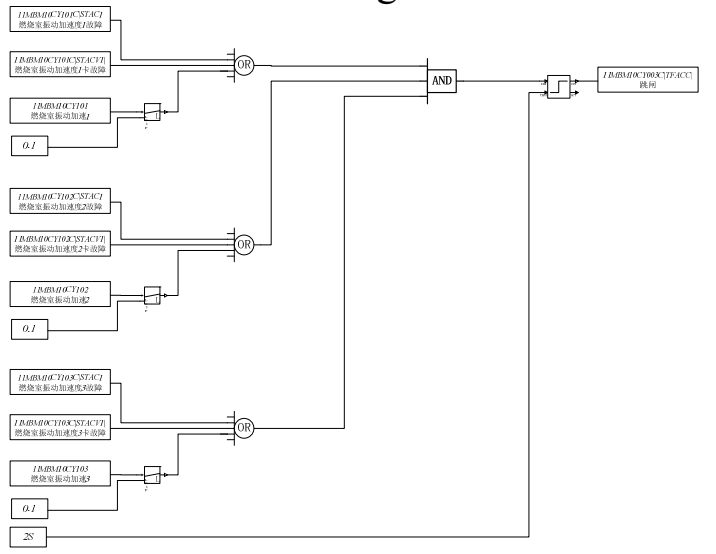

Fig. 11 Burning room ACC protection logic framework IV

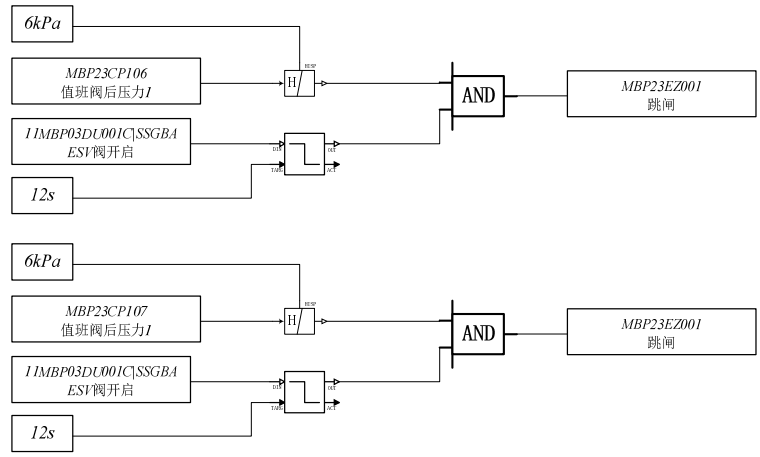

Fig. 12 ignition protection logic framework

Protection of the ignition over fuel.During the ignition process, if there is too much fuel get into the burning room, then the combination of the fuel and the air is not great, can not let to the fuel burnt to the end, thus may contain safety issue[3]. The protection system after 12s of ESV (safe 
ignition time), if the pressure is more than $6 \mathrm{kpa}$, then there is a possibility of too much fuel get in the room. When this occur, worker should discontinue the engine, start again after wait for a while.

Ignition fuel protection through Siemens transmitter detect natural gas pressure. When the number is reach certain limits, transmitter can distribute all these signals. Thus can achieve the protection work.

\section{Suggestion of the program that need to be upgraded}

Lubricant liquid level upgrade. Lubricant as the mediate of the lubricant oil, the level of liquid is very important. Siemens set both high and low of the level as dangerous. Low level can trigger the damage of the tank, while high level can lead to too much cooling liquid get into the tank.

Lubricant tank have a long distance magnet detector. On the detector has High I, High II and Low I, Low II four segments. All the protection has switch 2 on 2 as protection. In order to avoid fault, set the third spot as testing spot, use the principal of 3 on 2 as liquid protection.

Natural gas over heated upgrade. Siemens engine T3000 protection, has temperature protection installed. ESV has three natural gas testing point. Any 2 out of 3 above 210 degree can lead to the close of the valve

The objective of this protection system is to prevent the possibility of explosion. However, most domestic design only have heating part, thus the protection system has no practical meaning, suggest to take it off.

Natural gas pre-install part's ESD protection upgrade. Siemens turbo charger T3000 protection, pre-install ESD valve close can lead to the close of the valve. Like the other "natural gas protection from low pressure", the react signal is singular, which can lead to mistake, thus suggest to take off this protection.

The upgrade of the low pressure of the compress air. Siemens turbo charger has its special design, to prevent valve to support the engine. It is the operator of the dual air intake, when the air is off, switch can not work. During the speed up process and the sudden stop of the valve, it should maintain open status. In order to keep the air, the design should involve protection system.

Turbo charger mode (air compress station), has three open, respectively 7Bar、6.7Bar and 6.7Bar. All of the judgment logic according to 3 from 2 .

Same domestic model of electric equipment, happens continue press decrease caused by pollution. After the air pressure lock is leased, can operate at most 10 minutes. When the alarm of "lower than 7 Bar" is on, can lead to the close of the valve in a short time.

In order to avoid things like this happen again, need to upgrade on these aspects:

1) Take the compressed air in to the can through automatic pressing valve as spare air resource. Need to make sure that all the pressure is higher than the fixed number.

2) Increase the testing spot of simulation pressure spot to monitor the pressure change.

3 ) Increase the alarm time of turbo. When the pressure is low, the turbo will start at the same time and will meet demand in one minute. If it takes more than one minute, then three is something wrong.

\section{Acknowledgement}

The valuable material from Shanghai turbo charging factory Shanghai electric equipment company, Nanjing Seimens automation company. At the same time thanks to the meaningful discussion and supportfrom Beijing bridge heat and electricity company, Beijing West gas company and Shenzhen Yuhu electric company.

\section{References}

[1] S. Jin, T. Qi and L. Shi: Interpretation of control system of Siemens turbo charger. China electric power press (2016). 
[2] S. Jin, T. Qi and B. Zhang:Natural gas-steam union cycle electricity technology and appliance guide book. China electric power press (2014).

[3] S.Zhang: Turbo charging engine control system . China electric power press( 2012). 